\title{
Responsible business practices: Aspects influencing decision-making in small, medium and micro-sized enterprises
}

\begin{abstract}
Authors:
Mrs Lynette Cronje ${ }^{1}$

Prof. Edmund John Ferreira ${ }^{1}$

Dr Sumei van Antwerpen ${ }^{1}$
\end{abstract}

\section{Affiliation:}

${ }^{1}$ University of South Africa (UNISA), South

Africa

\section{Correspondence to:}

Prof. Edmund John Ferreira, Department of Business Management,

PO Box 392,

UNISA 0003,

South Africa

\section{E-mail:}

eferreir@unisa.ac.za

ORCID iD:

http://orcid.org/0000-00022862-4806

DOI:

10.15249/11-1-143

\section{Keywords:}

responsible business practices; small, medium and microsized enterprises; South Africa; corporate social responsibility; SMME owners; small businesses; SMEs; decision-making

\section{Abstract}

Society demands responsible business practices (RBP) from all businesses, including small, medium and micro-sized enterprises (SMMEs). The conscious decision to partake in RBP resides with the main decision-makers of SMMEs. This article identifies which aspects influence the decision-makers of SMMEs to utilise business resources for RBP, and the different demographic variables that impact on these influencing aspects. Responses from 84 SMMEs indicate that the company's current financial condition is the greatest influence for SMMEs, while ethics only influences SMMEs to a moderate extent. The age, education level and gender of the decision-makers all have an impact on these influencing aspects.

\section{Introduction}

It is becoming an inescapable priority for businesses to act in a responsible manner and give back to their community and the environment through various initiatives. While society demands social responsibility actions from all businesses, including SMMEs, responsible businesses strive to have a positive effect on the communities and environments they operate in.

The term 'responsible business practices' (RBP), as used in this article, indicates the practices SMMEs follow or partake in, in order to act responsibly towards their stakeholders and their operating environments. The Institute for Business Ethics (2010) points out that RBP is important for the success of SMMEs. Successful SMMEs use their social programmes to strengthen their image and to be more competitive (Dincer \& Dincer, 2013; Jenkins, 2006). The European Commission (2013) identified 
other motivating factors for SMMEs to engage in RBP, namely: (1) tangible benefits such as positive economic outcomes and intangible business benefits such as reputation and trust; (2) personal values - which is part of the business' overall culture; (3) institutional factors such as legal requirements; and (4) to fulfil stakeholder expectations.

While the motivation for partaking in RBP originates from various sources, the conscious decision to do so still resides with the main decision-makers of SMMEs. These decisionmakers seek and evaluate information and alternatives before coming to a conclusion. Decision-making in SMMEs is different from decision-making in larger firms as the processes begin with and involve owners/managers to a large extent (Hsu \& Cheng, 2012; Walsh \& Lipinski, 2009). Large businesses tend to have a structured framework with a clear hierarchy in decision-making (Garengo, Biazzo \& Bititci, 2005; Walsh \& Lipinski, 2009) and decisions will not typically be subject to personal influence. In SMMEs, ownership and control mostly reside with the same person and this lends legitimacy to personal decisions made on how to expend company resources, such as on RBP-related initiatives (Jenkins, 2006). The decision-makers in SMMEs mainly draw on their experience, knowledge and a variety of social ties to form their judgement (Westhead, Ucbasaran \& Wright, 2009). The decision to utilise business resources for RBP is influenced by various aspects that differ in small and large enterprises (Dincer \& Dincer, 2013; Hsu \& Cheng, 2012; Moore \& Spence, 2006).

While the concept and approach of responsible business practices (RBP) is advancing in application, the academic research on RBP in SMMEs has been lacking and rather limited empirical evidence can be found about RBP of SMMEs in contrast to larger businesses. Most social responsibility actions research focus on the broader literature of corporate social responsibility (CSR) and larger businesses (Campin, Barraket \& Luke, 2013; Dincer \& Dincer, 2013; Moore \& Spence, 2006; Perrini, Russo \& Tencati, 2007). Small businesses may be small individually, but their total cumulative impact on the community and on society is significant (Nejati \& Amran, 2013). Literature indicates that the findings in CSR research cannot always be generalised to SMMEs, as definitions of "acting responsibly" vary between the settings of large and small businesses (Dincer \& Dincer, 2013; Moore \& Spence, 2006; Perrini et al., 2007). As a result of these differences in the definition, the term "CSR" can be seen as not entirely appropriate for SMMEs. Dincer and Dincer (2013), Hsu and Cheng (2012), Moore, Slack and Gibbon (2009) and Spence (2007) state that SMMEs might well be engaged in CSR either without knowing it or without calling it CSR, and that this can be linked to the issue of terminology.

Research on acting responsibly has been undertaken in countries such as Italy (Coppa \& Sriramesh, 2013; Perrini et al., 2007), India (Gupta, Sukhmani \& Kalra, 2012), Singapore (Lee, Mak \& Pang, 2012), England (Moore, Slack \& Gibbon, 2009), Germany (Hammann, Habisch \& Pechlaner, 2009) and Turkey (Dincer \& Dincer, 2013). No similar studies have been undertaken in South Africa. There is also a lack of studies that examine decisionmaking processes in SMMEs (Musso \& Francioni, 2012) and this is also the case when considering decision-making with specific regard to RBP activities (Dincer \& Dincer, 2013; Fatoki \& Chiliya, 2012; Lepoutre \& Heene, 2006; Moore \& Spence, 2006; Perrini et 
al., 2007). The main issues that have not been adequately addressed are those aspects that influence decision-makers in SMMEs to utilise business resources and funds for RBP that may or may not provide financial returns for the business (Dincer \& Dincer, 2013; Hauser, Cushman, Young, Jin \& Mikhail, 2007; Parboteeah, Hoegl \& Cullen, 2008).

This article aims to fill the gap in literature by discussing the findings from a selfadministered questionnaire which was distributed to 84 SMME decision-makers in the Tshwane region of the Gauteng province of South Africa. If different demographic variables are taken into account when making decisions, the understanding of which aspects influence the decision-makers to utilise business resources for RBP will increase. This article will proceed as follows: After a discussion of the literature base concerning CSR and RBP in SMMEs, an explanation of the multi-stage sampling methods will be provided and the structured questionnaire and primary data collection will be discussed, followed by the results and conclusions.

\section{Literature review}

The knowledge base for this article involves SMMEs, CSR and RBP and these will be discussed in this order.

\subsection{Small, medium and micro-sized enterprises}

SMMEs have specific characteristics that distinguish them from larger businesses (Dincer \& Dincer, 2013). While these characteristics can differ between countries and cultures, SMMEs are generally independent, based on personal relationships, actively managed by the owners, largely local in their areas of operation and largely dependent on internal sources for financial growth. SMMEs play a vital role in the economic and social environment of a country, especially in the case of developing countries with major employment and income distribution challenges - such as South Africa (Cant, Wiid \& Hung, 2013).

\subsubsection{SMMEs in South Africa}

The South African government is currently facing a major challenge in alleviating poverty and creating more sustainable jobs for the population. This is evident when observing the unemployment rate of $26.7 \%$ in the first quarter of 2016 (Statistics South Africa, 2016). The main motivation for starting an SMME is unemployment and having no alternative source of income (Statistics South Africa, 2014). This is also reflected in the Global Entrepreneurship Monitor (GEM) report (2015) which indicates that 33.2\% of the Total Entrepreneurial Activity (TEA) in South Africa arises from individuals starting businesses out of necessity for survival, when there is no other source of income and the individual concerned cannot get formal employment. These entrepreneurs do very little analysis and/or preparation before starting their businesses. Whatever the reason for starting these businesses, it is important to note that the contributions they make to the economic growth of a country are different from those made by larger businesses. 


\subsubsection{SMMEs versus larger businesses}

Nieman (2006) identified factors that set SMMEs apart from larger businesses. SMMEs create an ease of entry and start-up, foster closer relationships with customers and the community through personalised services and personal attention, form a vital link in the supply chain since they are often located where larger businesses would not consider establishing themselves, are vital in the supply chain of larger businesses since they are closer to the consumer and provide employees with comprehensive learning experiences, develop risk takers, and generate employment opportunities. They are not restricted to formally registered enterprises (such as close corporations, private and co-operative enterprises) but include informal and non-VAT (Value-Added Tax) registered enterprises such as survivalist street trading enterprises, backyard manufacturing and services, and occasional home-based evening jobs (the dti, 2008). For the purposes of this article, only formal SMMEs were investigated since they have a continuous income from trade and are therefore more likely to expend resources on RBP.

\subsubsection{Management functions in SMMEs}

SMMEs all have owners/managers who are responsible for the managerial activities of the business. Management is necessary to combine and direct the resources of the business so it can achieve goals as efficiently and productively as possible (Van Aardt, 2013). The basic functions of managers are planning, organising, leading and control (Brevis \& Vrba, 2014). Although these fundamental functions remain the primary task of the SMME owner/manager and should be undertaken continuously for the business as a whole, the business should also be supported by other roles, such as that of decision-making. Decision-making cannot be understood simply by studying final decisions - there is an emotional, perceptual and cognitive process involved that finally leads to the chosen alternative (Svenson, 1979). The decision-maker seeks and evaluates information and alternatives before coming to a conclusion. Strategic decisions lead to the commitment of resources and people to certain courses of action (Jansen, Curşeu, Vermeulen, Geurts \& Gibcus, 2011). Regardless of the decision that needs to be made, influencing aspects are always present in the process. The aspects that can influence and have an impact on decision-making in general include peer pressure (Westerman, Beekun, Stedham \& Yamamura, 2007; Hanson \& Moore, 2013), emotions (Stanley, 2010), ethics (Hanson \& Moore, 2013), financial position (Rodgers \& Gago, 2004), cognitive style and personality (Filbeck, Hatfield \& Horvath, 2005), culture (Dimitratos, Petrou, Plakoyiannaki \& Johnson, 2011; Westerman et al., 2007), integrity and honour (Hanson \& Moore, 2013), age, gender, moral maturity, religious beliefs (Hanson \& Moore, 2013; Hilary \& Hui, 2009; Phipps, 2012), and social media (Power \& Phillips-Wren, 2011). Decision-making differs, however, in SMMEs and larger firms. In SMMEs, the ownership and control mostly reside with same person and this lends legitimacy to the personal decisions made on how to expend company resources, such as in RBP-related initiatives (Jenkins, 2006). Decision-makers in SMMEs are the central point where all business activities start and they have a considerable influence on the SMMEs' (future) direction (Hammann et al., 2009). Decision-making is one of the critical drivers of organisational performance and 
non-alignment will likely lead to problems in the medium to long term (O'Regan, Sims \& Ghobadian, 2005). Other problems are demonstrated in studies by Gaskill, Van Auken and Manning (1993) and Stokes and Blackburn (2002) who found that failure to make timely business decisions proves harmful to a business and may lead to business failure. This was confirmed in the study done by Ahmad and Seet (2009). Gaskill et al. (1993) also found that poor decision-making was due to inadequate skills that lead to financial problems. However, decision-makers who are better equipped to act in a decision situation will rely on their skills to navigate through it. The higher their confidence level and level of risk acceptance, the higher their decision effectiveness will be (Jansen et al., 2011) in the making of decisions that will lead to the commitment of resources to a course of action, such as acting in a socially responsible manner. Influences on RBP decision-making in particular will be discussed after the theory base for the concept has been explained.

\subsection{Corporate social responsibility}

CSR is a well-known concept that, although difficult to define, can be described as a business's responsibility to sustain itself through balanced relationships with society and the environment in which it operates (Faragher, 2008). The list of the top ten most frequently used definitions of CSR in literature and on the internet was compiled by Dahlsrud (2008). The frequency counts of each definition were categorised to five different dimensions of CSR, namely environmental (the natural environment), social (the relationship between the business and society), economic (socio-economic or financial aspects), stakeholder (stakeholders or stakeholder groups) and voluntariness (actions not prescribed by law). The word cloud, presented in Figure 1, reflects the most prominent dimensions of CSR (Dahlsrud, 2008). The most conspicuous dimensions are presented in a larger font size.

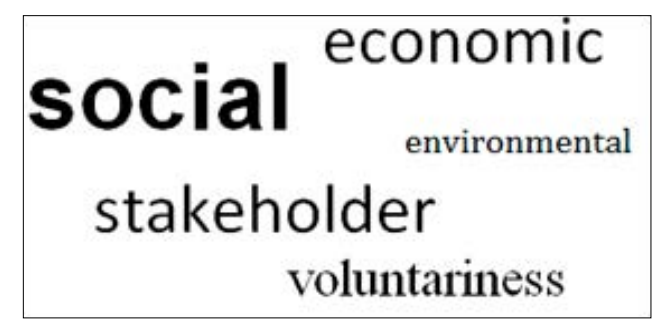

Figure 1: Most prominent dimensions of CSR

'Social' followed by 'economic' and 'stakeholder' are the most prominent dimensions of CSR. This indicates that the relationship between business and society is the most vital when considering how the business operates in terms of responsibility and sustainability. While CSR is mostly implemented by large businesses, the total cumulative impact of small businesses on the community and society is significant (Nejati \& Amran, 2013). Some of the main differences between CSR in large businesses and CSR in SMMEs are listed in Table 1. 
Table 1: Differences in CSR among large and small businesses

\begin{tabular}{l|l|l}
\hline & Large businesses & Small businesses \\
\hline Formalisation of CSR & Formal, bureaucratised & Informal \\
\hline Main actors in CSR & Shareholders, external stakeholders & Owner/manager, employees \\
\hline Aims of CSR & $\begin{array}{l}\text { Build corporate brand and manage } \\
\text { public legitimacy }\end{array}$ & $\begin{array}{l}\text { Build trust, networks and personal } \\
\text { relations }\end{array}$ \\
\hline
\end{tabular}

Source: Crane, Matten \& Spence, 2014:12

There are a number of reasons that account for these differences. Firstly, SMMEs are informal in nature and do not have a need for formal systems and structures. This indicates that in SMMEs, the organisational hierarchy, charts and processes are not necessarily written down and official (formal), but are more relaxed and unofficial. Secondly, unlike large businesses, SMMEs are less visible in the sense that only the local community will be aware of their RBP activities, and not larger audiences. Their key relationships are on a personal level. Thirdly, there is no separation of ownership and control, unlike in large firms. Owner/managers are not obliged to serve shareholders or seek to maximise return on investment, but enjoy the autonomy of running their own firms. This allows them to invest time and resources according to their stakeholders' interests (Crane et al., 2014).

Given the importance of SMMEs, the CSR literature has, to date, paid disproportionate attention to larger businesses. Findings from CSR research are not necessarily applicable in the SMME context as 'acting responsibly' differs between the settings of large businesses and SMMEs (Dincer \& Dincer, 2013; Moore \& Spence, 2006; Perrini, Russo \& Tencati, 2007). Since this CSR theory is not directly applicable to SMMEs, the term can be seen as not entirely appropriate. Spence (2007), Moore, Slack and Gibbon (2009), Dincer and Dincer (2013), as well as Hsu and Cheng (2012) state that SMMEs might well be engaged in CSR without knowing it, or without calling it CSR, and this can be linked to the issue of terminology. Therefore, it is imperative to understand the terminologies used in different businesses.

\subsection{Responsible business practices}

The term RBP is used in this article and indicates the practices SMMEs follow or partake in to act responsibly towards their stakeholders and their operating environments. To justify the use of the term, evidence was found in a study by Nejati and Amran (2013) whose research revolved around the terminologies used among 100 SMMEs for acting in a socially responsible manner. The six terms found to be the most common are: (1) responsible business practices; (2) corporate social responsibility; (3) social/societal engagement; (4) environmental involvement; (5) beneficial relationship with society;

(6) sustainable development/business practice. RBP was the term used by $43 \%$ of the small businesses that were surveyed.

RBP is important for the success of SMMEs (The Institute for Business Ethics, 2010). Successful SMMEs use their social programmes to strengthen their image and to be more competitive (Jenkins, 2006; Dincer \& Dincer, 2013; Pastrana \& Sriramesh, 2014). The 
benefits of RBP, for large firms and SMMEs, include benefits to both the business and its internal and external stakeholders. According to Adamu and Yahaya (2014) benefits for the business can include sales and profit growth, community goodwill, access to local talent, customer loyalty, an increased customer base, employee loyalty, increased productivity and a motivated workforce. The benefits to the stakeholders include reduced local unemployment, community contribution, social and economic inclusion, social cohesion in the community, customer satisfaction, job satisfaction, skills development, and employability. Pastrana and Sriramesh (2014) add that RBP activities (for example, being involved in environmental programmes or local schools and/or charities) can lead to an improved organisational culture, attracting and retaining the best employees, having improved incentives for managers and employees, improved management quality and improved customer loyalty.

\subsection{RBP decision-making}

For the SMME to receive all these benefits, a conscious decision must be made to partake in RBP. Analysis of literature indicates that many aspects can potentially influence the decision of SMMEs to utilise business resources for RBP activities and that the aspects that affect decisions in large businesses are different from the aspects that influence the decision-makers in SMMEs (Lepoutre \& Heene, 2006; Moore \& Spence, 2006). SMMEs partake in different RBP activities for various reasons. The reasons, or aspects, that influence owners/managers in their decision-making process to decide which activities to participate in will also differ from one SMME to the next, and also between the decision-makers as individuals. Even though acting responsibly as a business takes place at organisational level, it is individual actors who make decisions and execute these initiatives (Aguinis \& Glavas, 2012). SMME decision-makers have the opportunity to directly shape their own businesses' practices according to their personal values and to endorse values other than profit (Spence, 1999).

There is a relative scarcity of individual-level studies in CSR (Aguinis \& Glavas, 2012; Dincer \& Dincer, 2013) and therefore in RBP decision-making theory. Decision-makers are influenced by numerous aspects when facing a certain decision (Fernandez-Huerga, 2008). Aspects that were found to influence RBP decision-making in other studies include personal feelings and emotions (Dincer \& Dincer, 2013; McCuen \& Shah, 2007), values (Hammann et al., 2009; Mudrack, 2007) business finances (Dincer \& Dincer, 2013; Rodgers \& Gago, 2004), requests from friends and family (Coppa \& Sriramesh, 2013; Dincer \& Dincer, 2013; Westerman et al., 2007), religion (Dincer \& Dincer, 2013; King, 2006), competitive reasons (Cochius, 2006), morals (Dincer \& Dincer, 2013; Rupp, 2011), and ethics (Dincer \& Dincer, 2013). Morals are the underlying principles on which individuals base their decisions, while ethics is the application of morals to decisions (Van Wyk, 2016).

This article aims to determine what the aspects are that influence decision-makers of SMMEs in Tshwane, South Africa, and the relationships that exist between these aspects 
and the demographic profile of the individuals. Based on the literature review, the following research questions $(\mathrm{RQ})$ were identified:

RQ1: What are the aspects that influence SMME decision-makers to spend resources on RBP?

RQ2: What is the relationship between the aspects identified and the (a) age; (b) highest level of education; and (c) gender of the decision-maker of the SMME?

\section{Methodology}

Following a positivistic paradigm, a quantitative research approach was employed. Causality was established by measuring the aspects influencing RBP decision-making in Tshwane SMMEs using a survey strategy. The research approach followed was inductive and this is appropriate since the study aims to draw a conclusion from the results which are used to suggest an explanation for behaviours that have been observed (Anderson, 2004). A general prediction is made that aspects influencing decision-making in South African SMMEs regarding RBP will correspond with those identified in other studies, as previously discussed.

\subsection{Sample}

The population of the study was comprised of SMMEs (as defined by the South African National Small Business Act 102 of 1996) based in Tshwane in the Gauteng province of South Africa. This study required the selection of a sample from a population that cannot easily be listed for sampling purposes. There are hardly any databases enabling one to estimate the size of the formal SMME population in South Africa (the dti, 2008). Therefore, it was impossible to determine the population of SMMEs in Tshwane. It was thus decided that the online directory (public domain), Brabys (www.brabys.com), would be used to determine a sample through multi-stage sampling. Formal SMMEs from the three largest formal SMME sectors (the dti, 2008) listed on the online database, Brabys, was the population of the study. Therefore, possible participants were SMMEs in the (1) financial intermediation, insurance, real estate, and business services; (2) wholesale and retail trade, repair of motor vehicles and motorcycles, personal and household goods, hotels and restaurants; and (3) manufacturing sectors. These formal sectors of the economy were selected as the population since they have a continuous income from trade and are therefore more likely to expend resources on RBP.

\subsubsection{Sampling Stage 1 - Nonprobability purposive sampling}

Since it was not possible to produce a complete list of the population, and since a sampling frame could not be developed, nonprobability sampling was appropriate. Firstly, identification of SMMEs listed on Brabys.com under the three different sectors started with a search of the directory. Businesses were searched by sector component (Sector 1 search terms: financial intermediation, insurance, real estate, business services; 
Sector 2 search terms: wholesale trade, retail trade, motor vehicle repair, motor cycle repair, personal goods, household goods, hotels, restaurants; Sector 3 search terms: manufacturing). Secondly, the search results were analysed and narrowed down to include only those businesses located in the Tshwane district. Finally, each listing was analysed to see if it qualified as an SMME. SMMEs were thus identified by visiting their websites (if applicable) and/or getting into contact with the contact person of the business (as listed on Brabys.com) via telephone to determine the number of persons employed. If the number of employees was under 200 people, the business was included in the sampling frame. This process resulted in a complete sampling frame from which a sample was drawn in the next stage.

\subsubsection{Sampling Stage 2 - Probability systematic sampling}

After the sampling frame was determined (a list of appropriate SMMEs - as discussed in Stage 1), the probability sampling method, systematic sampling, was used. This method is appropriate since a systematic sample can be determined without an accurate list of the entire population (which, in the case of this study, was unavailable) by substituting the number of elements in the sample frame for the population's size (Cooper \& Schindler, 2011). The systematic sampling process followed the steps as suggested by Cooper and Schindler (2011). The following formula helped determine the skip interval to use when selecting the final sample:

$$
\text { Skip interval }(a)=\frac{\text { Sample frame size }(b)}{\text { Sample size }(c)}
$$

The sample size needed for the study was 150 respondents. The researcher determined the sample frame size to be 1146 SMMEs. As per the above formula, the skip interval was determined by dividing the sample frame size (1146) by the sample size (150). The skip interval was therefore 7.64 and every 8 th SMME was included in the final sample. The random start element was selected as the first (one), and a sample was drawn choosing every 8th SMME. The participating SMMEs varied in size, ownership and industry affiliation. The decision-makers in these businesses were owners/managers (decisionmakers) who represent a wide range in personal demographics.

The final sample size of the study was 164 SMMEs. A total of 170 questionnaires were distributed. Although 150 was the requirement, the response from the SMMEs was very positive, and 164 questionnaires were received and used in the analysis. However, in the questionnaire, it was necessary to include two filter (skip) questions quite early to eliminate respondents who did not have the authority to make business decisions, as well as SMMEs who did not engage in RBP. Due to these questions, for the purpose of this article (which reports only on the influencing aspects and the demographic variables of the respondent) the total number of usable questionnaires was 84 . 
Following a literature review, aspects influencing RBP decision-making in SMMEs were identified. Table 2 provides a summary of the aspects considered. Measurement items associated with the aspects listed in Table 2 were obtained from the listed references.

Table 2: Aspects found to influence RBP decision-making

\begin{tabular}{l|l}
\multicolumn{1}{c|}{ Aspect } & \multicolumn{1}{c}{ Reference(s) } \\
\hline Personal feelings and emotions & Dincer \& Dincer, 2013; McCuen \& Shah, 2007 \\
\hline Morals & Dincer \& Dincer, 2013; Rupp, 2011 \\
\hline Ethics & Dincer \& Dincer, 2013 \\
\hline Business finances & Dincer \& Dincer, 2013; Rodgers \& Gago, 2004 \\
\hline Requests from friends and family & $\begin{array}{l}\text { Coppa \& Sriramesh, 2013; } \\
\text { Dincer \& Dincer, 2013; Westerman et al., 2007 }\end{array}$ \\
\hline Religion & Dincer \& Dincer, 2013; King, 2006 \\
\hline Competitive reasons & Cochius, 2006 \\
\hline
\end{tabular}

To ensure validity, the questionnaire was reviewed from a data perspective by a qualified statistician and from a respondent perspective by three colleagues of the author. One rating question was used to collect opinion data. A five-point Likert rating scale was used to enable respondents to rate the extent to which each aspect influences their decision-making. Multiple-choice and dichotomous questions were used to determine the demographic profile of the respondents.

\subsection{Data collection and analysis}

Primary data collection took place over a period of one month. The structured questionnaires were distributed by two fieldworkers using three methods. Depending on the preference of the SMME decision-maker these were: (1) waiting while respondents completed the questionnaire and collecting it directly from them; (2) dropping off the questionnaire and picking it up at a later stage; or (3) e-mailing the questionnaire (electronically). Fieldworkers signed a confidentiality form to agree to confidential and anonymous information gathering, as well as a contract to complete the work. Fieldworkers were trained by the researcher on the aims of the study, as well as the structure of the questionnaire.

Following data collection, the coding and capturing of the data onto a Microsoft Excel spread sheet commenced. Thereafter it was exported to SPSS to produce tables and to do a statistical analysis. In order to measure the association between two variables, the analysis considered Cramer's V, Mann-Whitney U and Kruskal-Wallis tests (Cooper \& Schindler, 2014; Saunders, Lewis \& Thornhill, 2009). A factor analysis was conducted on the Likert scale question that asked respondents to rate the extent that the aspect influenced them in their decision-making. The aspects were found to be one dimensional and it was decided to test each aspect separately, therefore no Cronbach Alpha value was applicable. 
The research was conducted ethically and special attention was given to confidentiality and anonymity, fairness, honesty and protection from harm and discomfort. Formal ethical clearance was obtained from Unisa (Ref \#: 2014_CEMS_BM_018) for the study on which this article is based.

\subsubsection{Limitations}

Firstly, it was difficult to obtain a comprehensive list of SMMEs due to the lack of a complete database in South Africa (and Tshwane). The list was compiled from a public directory, however not all SMMEs have listings in this directory. Secondly, the study only focused on SMMEs in the Tshwane district of South Africa. While the results are not intended to be generalised to a larger population given the nature of the sampling plan, it is still possible for other domains with the same characteristics to benefit from the findings of the article.

\section{Results}

The results report on the respondents' demographic profile, the aspects found to influence Tshwane SMME decision-makers when making RBP decisions and the relationship between these variables.

\subsection{Demographic profile}

The cumulative majority ( $80 \%)$ of the SMME decision-makers formed part of the categories 30-39 years and 40-49 years of age. The other categories were 50-65 years $(16 \%)$ and $18-29$ years (4\%). Almost two thirds $(62 \%)$ of the respondents were male. The respondents' highest level of education was based on the South African National Qualifications Framework set out by the South African Qualifications Authority (SAQA) and referred to as NQF levels. The qualification level of respondents varied widely with 34 (40.5\%) indicating NQF levels one to four (a Junior Certificate - Grade 9 to 11 or Standard 7 to 9; a National Senior Certificate - Matric or Grade 12 or Standard 10 or alternatively a Trade Certificate); 35 (41.7\%) indicating NQF levels five to seven (a Higher Certificate, a National Diploma or Advanced Certificate; a Bachelors Degree of 3 years; or an Advanced Diploma); and 15 (17.9\%) indicating NQF levels eight and nine (an Honours Degree or a Post Graduate Diploma; or a Master's Degree). A total of $25(30 \%)$ of the respondents indicated that their SMMEs were operating in the manufacturing sector. A total of 33 $(40 \%)$ of the respondents indicated that their companies were operating in the financial intermediation, insurance, real estate, and business services sector; and $25(30 \%)$ of the respondents indicated that their companies were operating in the wholesale and retail trade, repair of motor vehicles and motor cycles, personal and household goods, hotels and restaurants sector. 


\subsection{Aspects influencing RBP decision-making}

To determine which aspects influence decision-making regarding RBP, respondents were asked to rate seven different aspects on a five-point Likert-type scale. The influencing aspects were: (1) personal feelings and emotions; (2) ethics; (3) morals; (4) current financial condition of the company; (5) requests from friends and family; (6) religion; and (7) competitive reasons. The respondents had to rate each aspect on the extent to which it influences them when making decisions to spend on any RBP activity. The scale points ranged from 1 (not at all) to 5 (always). The percentages of responses for each point on the scale are summarised in Figure 2.

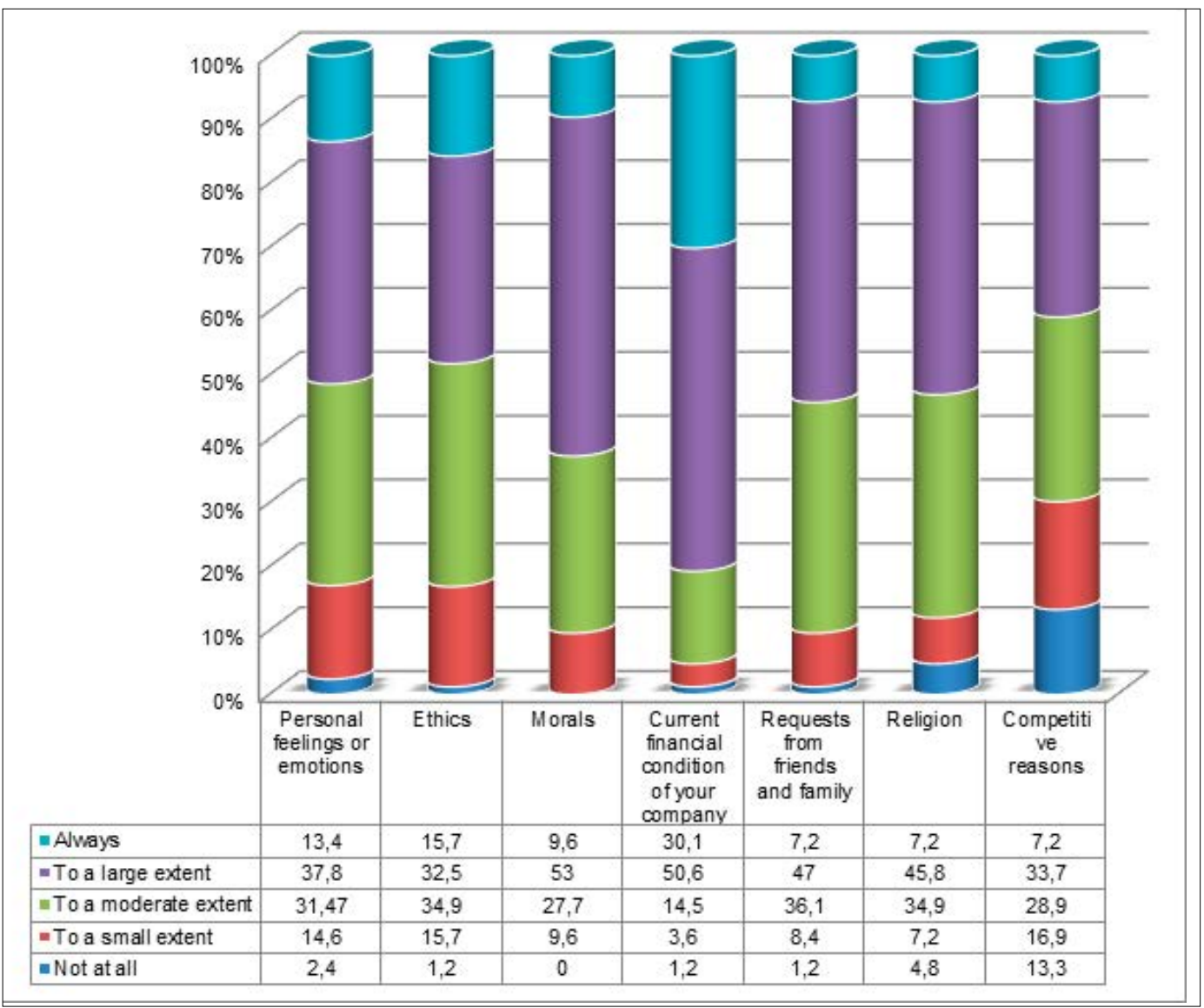

Figure 2: Extent to which aspects influence RBP decision-making

It is evident from Figure 2 that most of the aspects influence respondents to a large extent, except for ethics where 'to a moderate extent' is higher than 'to a large extent'. It can also be seen that the current financial condition of the company has the highest percentage of all the aspects, both under 'to a large extent' and 'always'. This result indicates that all of the influencing aspects mentioned in the literature review indeed influence RBP decision-making of SMMEs in Tshwane. 


\subsection{Relationship between the influencing aspects and the demographic variables}

Firstly, the Kruskal-Wallis test was used to determine statistically significant differences between: (1) The age groups of respondents with regard to the aspects influencing RBP decision-making; and (2) The respondent's highest level of education with regard to the aspects influencing RBP decision-making. Finally, the Mann-Whitney test was used to determine if a statistically significant difference between the male and female respondents with regard to the aspects influencing RBP decision-making exists. The following hypotheses were formulated:

$\mathrm{H}_{1}$ : There is a difference between the age group of respondents with regard to each of the aspects influencing RBP decision-making.

$\mathrm{H}_{2}$ : There is a difference between the respondent's highest level of education with regard to the aspects influencing RBP decision-making.

$\mathrm{H}_{3}$ : There is a difference between male and female respondents with regard to the aspects influencing RBP decision-making.

\subsubsection{Key differences between age groups $\left(\mathrm{H}_{1}\right)$}

Firstly, a statistically significant difference between the age group of respondents with regard to one influencing aspect (current financial condition of the business) was observed and $\mathrm{H}_{1}$ was accepted. The results of the Kruskal-Wallis test are shown in Table 3.

Table 3: Kruskal-Wallis test results for the difference between the age group of respondents with regard to the aspects influencing RBP decision-making

\begin{tabular}{l|l}
\hline & Current financial condition of the business \\
\hline Chi-Square & 8.189 \\
\hline df & 2 \\
\hline Asymp. Sig. & .017 \\
\hline
\end{tabular}

This result indicates that there is a statistically significant difference, at the $5 \%$ level of significance, between the age group of respondents with regard to one aspect (current financial condition of the business) influencing RBP decision-making.

Mean ranks indicate that the age group of 50 to 59 years tends to be less influenced by their business' current financial condition (mean: 24.65) than the other age groups. The 40 to 49 years group tend to be most influenced by this aspect (mean: 43.36) with the 30 to 39 years group only slightly less (mean rank: 41.61). The 18 to 29 years group was not included due to the small number of respondents in this group.

\subsubsection{Key differences between respondents' highest level of education $\left(\mathrm{H}_{2}\right)$}

Next, it was determined that there is a statistically significant difference between the respondent's highest level of education with regard to one influencing aspect (ethics). Therefore, $\mathrm{H}_{2}$ was accepted. The results of the Kruskal-Wallis test are shown in Table 4. 
Table 4: Kruskal-Wallis test results for the difference between the highest level of education with regard to the aspects influencing $\mathrm{RBP}$ decision-making

\begin{tabular}{l|l}
\hline & Ethics \\
\hline Chi-Square & 6.588 \\
\hline df & 2 \\
\hline Asymp. Sig. & .037 \\
\hline
\end{tabular}

This result indicates that there is a statistically significant difference, at the $5 \%$ level of significance, between the respondents' highest level of education with regard to this aspect (ethics) influencing RBP decision-making.

Mean ranks indicate that respondents' whose highest qualification is on NQF level five, six or seven, are the most influenced by ethics when making RBP decisions (mean rank: 49.51). Respondents' whose highest qualification is on NQF level eight or nine are the least influenced by ethics (mean rank $=34.43$ ).

\subsubsection{Key differences between genders $\left(\mathrm{H}_{3}\right)$}

Thirdly, it was determined that there is a statistically significant difference between male and female respondents with regard to four of the seven influencing aspects namely personal feelings, ethics, morals and religion. Therefore, $\mathrm{H}_{3}$ was accepted. The results of the Mann-Whitney test are shown in Table 5.

Table 5: Mann-Whitney test results for difference between genders with regard to the aspects influencing RBP decision-making

\begin{tabular}{l|c|c|c|c}
\hline & $\begin{array}{c}\text { Personal feelings } \\
\text { or emotions }\end{array}$ & Ethics & Morals & Religion \\
\hline Mann-Whitney U & 577.500 & 551.000 & 603.000 & 586.000 \\
\hline Wilcoxon W & 1955.500 & 1929.000 & 1981.000 & 1964.000 \\
\hline Z & -2.045 & -2.509 & -2.100 & -2.232 \\
\hline Asymp. Sig. (2-tailed) & .041 & .012 & .036 & .026 \\
\hline
\end{tabular}

This result indicates that there is a statistically significant difference, at the $5 \%$ level of significance, between male and female respondents with regard to these four aspects influencing their decision-making on RBP.

The mean ranks indicate that females' decision-making is more influenced by all four of these aspects than males (mean ranks of personal feelings: $48.25 \mathrm{vs.} \mathrm{37.61;} \mathrm{mean} \mathrm{ranks} \mathrm{of}$ ethics: 50.23 vs. 37.10 ; mean ranks of morals: 48.55 vs. 38.10 ; and mean ranks of religion: 49.10 vs. 37.77 ). This result indicates that, when making a decision regarding RBP, females are more likely to consider their personal feelings, ethics, morals and religion than males. 


\subsection{RQ1: The aspects influencing SMME decision-makers to} spend resources on RBP

All the aspects identified in the literature review, namely personal feelings and emotions, ethics, morals, current financial condition of the company, requests from friends and family, religion and competitive reasons are applicable to SMMEs in Tshwane, South Africa. Personal feelings or emotions, morals, the current financial condition of the company, requests from friends or family, religion and competitive reasons all influence respondents to a large extent. Ethics only influences SMMEs to a moderate extent while the current financial condition of the company is the greatest influence for SMMEs.

The results correspond with the literature review (references listed in Table 2). Having knowledge about the different influencing aspects, it can be concluded that while all of the aspects influence individuals when making a decision, this will be to varying degrees that differ from one individual to the next and from one business to the other. SMMEs should take into account that the influencing aspects identified are both personal and business related and that the extent to which each individual aspect influences the decision-maker's choices will differ. The fact that ethics influences the SMMEs' decisionmaking process only to a moderate extent is problematic. This result reveals that SMMEs are more focused on the profits of the business than on acting in an ethical manner. It is also possible that respondents do not understand the difference between morals and ethics. Considering this result, it can be concluded that the behaviours and patterns of decision-making in SMMEs could be improved.

Considering that the current financial condition of the company is the greatest influence when deciding to spend resources on RBP activities, it can be concluded that if an SMME is in a bad financial state, they will most likely not partake in RBP. This corresponds with the finding by Dincer and Dincer (2013) who stated that the financial position was a factor when the finances of the business were down. Therefore, the extent of RBP engagement depends on the available funds of the SMME.

\subsection{RQ2: The relationship between the aspects identified and the (a) age; (b) highest level of education; and (c) gender of the decision-maker of the SMME}

RQ2(a): The results of this study indicate that SMMEs with older decision-makers (50-59 years of age) are more likely to spend company resources on RBP regardless of their businesses' financial position. Tuzco (2014), after reviewing a number of studies, came to the conclusion that it is not possible to observe a strong association between age and CSR implementations in a large business. However, this study proposes that in an SMME, the decision-makers' age is indeed an influencing aspect. It is likely that older decision-makers realise that a poor financial condition is a temporary state and that, in the long term, acting responsibly could provide the business with invaluable benefits. It is possible that younger decision-makers lack the experience that their older counterparts 
possess. It is also possible that older decision-makers have more stable enterprises that have more money to spare for such activities.

RQ2(b): An interesting finding is that if the SMME decision-maker has an NQF level five, six and seven level of education, ethics is more important when deciding to be involved in RBP. This corresponds with Hsu and Cheng's (2012) finding that education levels have a positive influence on the SMME's willingness to engage in responsible business, and that the degree of influence of a graduate school education is stronger than that of other education levels. A possible cause for this finding could be that higher education institutions sometimes include ethics in their curriculum, and therefore the decisionmaker might have greater knowledge on the topic. It is possible that the decision-makers that are more knowledgeable have better management skills, and for this reason there are more resources available for RBP. The reason for NQF levels eight or nine being the least influenced by ethics is unclear, and no evidence was found in the literature to support this finding. Therefore, it is suggested that the difference between the decision-makers' highest level of education and ethics as an influencing aspect should be researched in more detail, together with the reason for ethics influencing RBP decision-making to only a moderate extent (see RQ1).

RQ2(c): It is interesting to note that RBP decision-making on the part of females is more influenced by personal feelings, ethics, morals and religion than is the case for males. From this result it can be concluded that these four aspects are more important to females and they are more likely to involve their emotions and personal values when making RBP decisions. No evidence was found in the literature to support these differences between males and females when making RBP decisions, and this is thus a suggestion for future research. The gender difference should be addressed by SMMEs through open communication and interaction. Males should be aware that females are influenced by personal emotions and values to a greater degree.

\section{Conclusion}

This article aimed to investigate the aspects influencing SMME decision-making for spending resources on RBP and the relationship of these aspects with the demographic variables of the decision-makers. Two research questions were set to achieve the purpose of the article, and it can be concluded that the study succeeded in its aim. From the discussion on the two research questions, it can be concluded that if different demographic variables are taken into account, the understanding of the aspects that influence the decision-makers to utilise business resources for RBP will increase.

This article contributes to the body of knowledge on decision-making in SMMEs. It also makes a contribution to South African SMME literature on doing responsible business and confirms the many aspects that are known to influence SMMEs to spend their resources on RBP. The aspects that were found to influence RBP decision-making could well be applicable to other conscious decision-making processes in SMMEs. The results and conclusions could also be of interest to SMMEs in other developing countries. 


\section{References}

Adamu, H.B. \& Yahaya, M.T. 2014. Social responsibility as a tool toward economic growth: Nigerian SMSEs' participation. International Journal of Sciences: Basic and Applied Research, 14(1):294-307.

Aguinis, H. \& Glavas, A. 2012. What we know and don't know about Corporate Social Responsibility: A review and research agenda. Journal of Management, 38(4):932-968. https://doi.org/10.1177/0149206311436079

Ahmad, N.H. \& Seet, P. 2009. Dissecting behaviours associated with business failure: A qualitative study of SMME owners in Malaysia and Australia. Asian Social Science, 5(9):98-104. https://doi.org/10.5539/ass. v5n9p98

Anderson, V. 2004. Research Methods in Human Resource Management. London: Chartered Institute of Personnel and Development.

Brevis, T. \& Vrba, M. (eds.). 2014. Contemporary Management Principles. Juta: Cape Town.

Byrd, M.J. \& Megginson, L. 2013. Small Business Management: An Entrepreneur's Guidebook. 7th edition. New York: McGraw-Hill.

Campin, S., Barraket, J. \& Luke, B. 2013. Micro-business community responsibility in Australia: Approaches, motivations and barriers. Journal of Business Ethics, 115:489-513. https://doi.org/10.1007/s10551-0121396-1

Cant, M.C., Wiid, J.A. \& Hung, Y. 2013. Small business owners' perceptions of business ethics and employee theft in the small business sector of South Africa. Corporate Ownership \& Control, 10(4):237-247. https:// doi.org/10.22495/cocv10i4c2art1

Cochius, T. 2006. Corporate Social Responsibility in Dutch SMEs: Motivations and CSR Stakeholders, Unpublished dissertation. Maastricht University, Netherlands.

Cooper, D.R. \& Schindler, P.S. 2011. Business Research Methods. 11th edition. New York: McGraw-Hill.

Cooper, D.R. \& Schindler, P.S. 2014. Business Research Methods. 12th edition. New York: McGraw-Hill.

Coppa, M. \& Sriramesh, K. 2013. Corporate social responsibility among SMEs in Italy. Public Relations Review, 39:30-39. https://doi.org/10.1016/j.pubrev.2012.09.009

Crane, A., Matten, D. \& Spence, L.J. 2014. Corporate Social Responsibility: Readings and cases in a global context. Routledge.

Dahlsrud, A. 2008. How corporate social responsibility is defined: an analysis of 37 definitions. Corporate Social Responsibility and Environmental Management, 15:1-13. https://doi.org/10.1002/csr.132

Delmar, F. \& Shane, S. 2003. Does business planning facilitate the development of new ventures? Strategic Management Journal, 24(12):1165-1185. https://doi.org/10.1002/smj.349

Dimitratos, P., Petrou, A., Plakoyiannaki, E. \& Johnson, J.E. 2011. Strategic decision-making processes in internationalisation: Does national culture of the focal firm matter? Journal of World Business, 46(2):194-204. https://doi.org/10.1016/j.jwb.2010.05.002

Dincer, B. \& Dincer, C. 2013. Corporate Social Responsibility Decisions: A Dilemma for SMME Executives? Social Responsibility Journal, 92.

Du Toit, G.S., Erasmus, B.J. \& Strydom, J.W. 2010. Introduction to Business Management. 8th edition. Oxford University Press: South Africa.

European Commission 2013. Corporate Social Responsibility for Small and Medium-Sized Enterprises. Compiled by Knopf, J. and Mayer-Scholl, B. http://ec.europa.eu/enterprise/policies/sustainable-business/ files/csr-SMME/tips-tricks-csr-SMME-advisors_en.pdf [Accessed 31 October 2014].

Faragher, J. 2008. Sustain to gain. Personnel Today, 20-22.

Fatoki, O. \& Chiliya, W. 2012. An investigation into the attitudes toward business ethics and corporate social responsibility by local and immigrant SMME owners in South Africa. Journal of Social Science, 32(1):13-21.

Fernandez-Huerga, E. 2008. The economic behaviour of human beings: The Institutional/Post-Keynesian model. Journal of Economic Issues, 42(3):709-726. https://doi.org/10.1080/00213624.2008.11507175

Filbeck, G., Hatfield, P. \& Horvath, P. 2005. Risk aversion and personality type. The Journal of Behavioural Finance, 6(4):170-180. https://doi.org/10.1207/s15427579jpfm0604_1 
FinScope. 2010. FinScope South African Small Business Survey. 2010. http://www.finscope.co.za/new/ scriptlibrary/getfile.aspx?filename=Brochure_FS_SMME_10.pdf\&file=../module_data/71e3e62d-1eeb-412e893b-970e98f6a3fa/downloads/a076179a-0814-4f0c-b176-c31dd7be19a0.file [Accessed 18 September 2013].

Garengo, P., Biazzo, S. \& Bititci, U.S. 2005. Performance measurement systems in SMEs: A review for a research agenda. International Journal of Management Reviews, 7(1):25-47.

Gaskill, L.R., Van Auken, H.E. \& Manning, R.A. 1993. A factor analytic study of the perceived causes of small business failure. Journal of Small Business Management, 31(4):18-31.

GEM. 2013. South African Report: 20 years of Democracy. Compiled by Herrington, M. \& Kew, J. http://www. gemconsortium.org/docs/3336/gem-south-africa-2013-report [Accessed 21 September 2014].

GEM. 2015. South African Report: Is South Africa heading for an economic meltdown? http://www. gemconsortium.org/country-profile/108 [Accessed 6 October 2016].

Gupta, S., Sukhmani \& Kalra, N. 2012. Impact of Corporate Social Responsibility on SMEs in India. Asia-Pacific Journal of Management Research and Innovation, 8(2):133-143. https://doi.org/10.1177/2319510X1200800206

Hammann, E., Habisch, A. \& Pechlaner, H. 2009. Values that create value: socially responsible business practices in SMMEs - empirical evidence from German companies. Business Ethics: A European Review, 18(1):37-51. https://doi.org/10.1111/j.1467-8608.2009.01547.x

Hanson, W.R. \& Moore, J.R. 2013. Ethical Decision-Making by Business Students: Factors of Influence. Electronic Journal of Business Ethics and Organization Studies, 18(1):15-26.

Hauser, M., Cushman, F., Young, L., Jin, R. \& Mikhail, J. 2007. A dissociation between moral judgments and justifications. Minds and Language, 22(1):1-21. https://doi.org/10.1111/j.1468-0017.2006.00297.x

Hilary, G. \& Hui, K.W. 2009. Does religion matter in corporate decision making in America? Journal of Financial Economics, 93(3):455-473. https://doi.org/10.1016/j.jineco.2008.10.001

Hsu, J. \& Cheng, M. 2012. What prompts small and medium enterprises to engage in corporate social responsibility? A study from Taiwan. Corporate social responsibility and environmental management, 19:288-305. https://doi.org/10.1002/csr.276

Institute for Business Ethics. 2010. Business Ethics for SMMEs. http://ibe.org.uk/userfiles/ briefing_6.pdf [Accessed 15 August 2013].

Jansen, R.J.G., Curşeu, P.L., Vermeulen, P.A.M., Geurts, J.L.A. \& Gibcus, P. 2011. Information processing and strategic decision-making in small and medium-sized enterprises: The role of human and social capital in attaining decision effectiveness. International Small Business Journal, 31(2):192-216. https://doi. org/10.1177/0266242611406762

Jenkins, H. 2006. Small business champions for corporate social responsibility. Journal of Business Ethics, 67(3):241-256. https://doi.org/10.1007/s10551-006-9182-6

King, S. 2006. The moral manager. Public Integrity, 8(2):113-133. https://doi.org/10.2753/PIN1099-9922080201

Lee, M.H., Mak, A.K. \& Pang, A. 2012. Bridging the gap: An Exploratory Study of Corporate Social Responsibility among SMEs in Singapore. Journal of Public Relations Research, 24(4):299-317. https://doi. org/10.1080/1062726X.2012.689898

Lepoutre, J. \& Heene, A. 2006. Investigating the Impact of Firm Size on Small Business Social Responsibility: A Critical Review. Journal of Business Ethics, 67(3):257-273. https://doi.org/10.1007/s10551-006-9183-5

McCuen, R. \& Shah, G. 2007. Implications of ethics education of recent neuroscience research on emotions. Journal of Leadership Studies, 1(3):44-56. https://doi.org/10.1002/jls.20024

Moore, G., Slack, R. \& Gibbon, J. 2009. Criteria for responsible business practice in SMMEs: An exploratory case of U.K. Fair Trade organisations. Journal of Business Ethics, 89:173-188. https://doi.org/10.1007/ s10551-008-9992-9

Moore, G. \& Spence, L. 2006. Editorial: Responsibility and small business. Journal of Business Ethics, 67(3):219-226. https://doi.org/10.1007/s10551-006-9180-8

Mudrack, P. 2007. Individual personality factors that affect normative beliefs about the rightness of corporate social responsibility. Business \& Society, 46(1):33-62. https://doi.org/10.1177/0007650306290312 
Musso, F. \& Francioni, B. 2012. The influence of decision-maker characteristics on the international strategic decision-making process: an SMME perspective. Procedia - Social and Behavioral Sciences, 58:279-288. https://doi.org/10.1016/j.sbspro.2012.09.1002

Nejati, M. \& Amran, A. 2013. Corporate social responsibility terminologies in small businesses: insights from Malaysia. Business Strategy Series, 14(1):11-14. https://doi.org/10.1108/17515631311295668

Nieman, G. 2006. Small business management: a South African approach. Van Schaik: Pretoria.

Nieuwenhuizen, C. 2011. Business management for entrepreneurs. 2nd edition. Juta: Cape Town.

O'Regan, N., Sims, M. \& Ghobadian, A. 2005. High performance: ownership and decision-making in SMMEs. Management Decision, 43(3):382-396. https://doi.org/10.1108/00251740510589760

Parboteeah, K., Hoegl, M. \& Cullen, J. 2008. Ethics and religion: An empirical test of a multidimensional model. Journal of Business Ethics, 80:387-398. https://doi.org/10.1007/s10551-007-9439-8

Pastrana, N.A.,\& Sriramesh, K. 2014. Corporate social responsibility: perceptions and practices among SMEs in Columbia. Public relations review, 40:14-24. https://doi.org/10.1016/j.pubrev.2013.10.002

Perrini, F., Russo, A. \& Tencati, A. 2007. CSR Strategies of SMMEs and Large Firms: Evidence from Italy. Journal of Business Ethics, 74(3):285-300. https://doi.org/10.1007/s10551-006-9235-x

Phipps, K.A. 2012. Spirituality and Strategic Leadership: The Influence of Spiritual Beliefs on Strategic Decision Making. Journal of Business Ethics, 106(2):177-189. https://doi.org/10.1007/s10551-006-9235-x

Power, D.J. \& Phillips-Wren, G. 2011. Impact of Social Media and Web 2.0 on Decision-Making. Journal of Decision Systems, 20(3):249-261. https://doi.org/10.3166/jds.20.249-261

Rodgers, W. \& Gago, S. 2004. Stakeholder influence on corporate strategies over time. Journal of Business Ethics, 52(4):349-363. https://doi.org/10.1007/s10551-004-1534-5

Rupp, D.E. 2011. An employee-centered model of organizational justice and social responsibility. Organizational Psychology Review, 1(1):72-94. https://doi.org/10.1177/2041386610376255

Saunders, M., Lewis, P. \& Thornhill, A. 2009. Research Methods for Business Students. 5th edition. UK: Pearson.

Spence, L.J. 1999. Does size matter? The state of the art in small business ethics. Business Ethics: A European Review, 8(3):163-174. https://doi.org/10.1111/1467-8608.00144

Spence, L.J. 2007. CSR and small business in a European Policy context: The five "C"s of CSR and small business research agenda 2007. Business and Society Review, 112(4):533-552. https://doi.org/10.1111/ j.1467-8594.2007.00308.x

Stanley, L.J. 2010. Emotions and Family Business Creation: An Extension and Implications. Entrepreneurship Theory and Practice, 34(6):1085-1092. https://doi.org/10.1111/j.1540-6520.2010.00414.x

Statistics South Africa. 2014. Survey of Employers and the Self-employed. http://beta2.statssa.gov.za/?p=3016 [Accessed 11 November 2014].

Statistics South Africa. 2015. Labour market dynamics in South Africa, 2014 report. http://www.statssa.gov. $\mathrm{za} / \mathrm{p}=4445$ [Accessed 16 September 2016].

Statistics South Africa. 2016. Media release - Quarterly Labour Force Survey. http://www.statssa.gov. $\mathrm{za} / \mathrm{p}=7281$ [Accessed 16 September 2016].

Stokes, D. \& Blackburn, R. 2002. Learning the hard way: the lessons of owner-managers who have closed their businesses. Journal of Small Business and Enterprise Development, 9(1):17-27. https://doi. org $/ 10.1108 / 14626000210419455$

Svenson, O. 1979. Process descriptions of decision making. Organisational Behaviour and Human Performance, 23:86-112. https://doi.org/10.1016/0030-5073(79)90048-5

the dti. 2008. Department: Trade and Industry, Annual review of small businesses in South Africa 2005-2007. www.dti.gov.za/SMME_development/docs/SMME_report.pdf [Accessed 5 June 2014].

Tuzco, A. 2014. The impact of corporate social responsibility perception on the job satisfaction and organizational commitment. Journal of the Faculty of Economics and Administrative Sciences, 4(1):185-202. 
Van Aardt, I. 2013. Principles of Entrepreneurship and Small Business Management. Oxford University Press: South Africa.

Van Wyk, I. 2016. Rationale of corporate citizenship. In: T. Botha (ed.). Corporate Citizenship. South Africa: Oxford University Press. 75-111.

Walsh, M.F. \& Lipinski, J. 2009. The role of the marketing function in small and medium sized enterprises. Journal of Small Business and Enterprise Development, 16(4):569-585. https://doi.org/10.1108/14626000911000929

Westerman, J., Beekun, R., Stedham, Y. \& Yamamura, J. 2007. Peers versus national culture: An analysis of antecedents to ethical decision-making. Journal of Business Ethics, 75(3):239-252. https://doi.org/10.1007/ s10551-006-9250-y

Westhead, P., Ucbasaran, D. \& Wright, M. 2009. Information search and opportunity identification. International Small Business Journal, 27(6):659-680. https://doi.org/10.1177/0266242609344255

Wiltbank, R., Dew, N., Read, S. \& Sarasvathy, S.D. 2006. What to do next? The case for non-predictive strategy. Strategic Management Journal, 27:981-998. https://doi.org/10.1002/smj.555 